Article

\title{
Chitosan Interaction with Iron from Yoghurt Using an In Vitro Digestive Model: Comparative Study with Plant Dietary Fibers
}

\author{
Marina Dello Staffolo ${ }^{1, *}$, Miriam Martino ${ }^{1}$, Alicia Bevilacqua ${ }^{1}$, Mirta Montero ${ }^{2}$, \\ María Susana Rodríguez ${ }^{2}$ and Liliana Albertengo ${ }^{2}$
}

1 Centro de Investigación y Desarrollo en Criotecnología de Alimentos (CIDCA), CONICET-CCT La Plata, Fac. Cs. Exactas, Universidad Nacional de La Plata, La Plata, 47 y 116, 1900, Argentina; E-Mails: mmartino@ing.unlp.edu.ar (M.M.); aebevila@ing.unlp.edu.ar (A.B.)

2 Instituto de Química del Sur (INQUISUR), CONICET-CCT Bahía Blanca, Departamento de Química, Universidad Nacional del Sur, Av. Alem 1253, Bahía Blanca, 8000, Argentina; E-Mails: mmontero@criba.edu.ar (M.M.); mrodri@uns.edu.ar (M.S.R.); alberten@criba.edu.ar (L.A.)

* Author to whom correspondence should be addressed. E-Mail: marinads@cidca.org.ar; Tel.: +54-221-4249287; Fax: +54-221-4254853.

Received: 5 May 2011; in revised form: 4 June 2011 / Accepted: 8 July 2011 /

Published: 19 July 2011

\begin{abstract}
The objective of this work was to investigate the interaction of chitosan with iron from yoghurt by an in vitro gastrointestinal tract model. Taking into account that chitosan is a polysaccharide included in fiber definition by Codex Alimentarius; chitosan behavior was studied and compared with different plant fiber (wheat, bamboo, apple, psyllium and inulin) behaviors, in the same in vitro conditions. Ferrous sulfate was added to yoghurts with each type of fiber. The gastric environment was simulated with $\mathrm{HCl}$ (pH 1.0-2.0). The duodenal environment was simulated with $\mathrm{NaHCO}_{3}(\mathrm{pH}$ 6.8-7.2) and a dialysis tubing cellulose membrane. Results showed that chitosan had the highest iron retention percentages $(53.2 \%$ at $30 \mathrm{~min} ; 56.8 \%$ at $60 \mathrm{~min})$ interacting in a more pronounced manner with iron than the plant fibers used in this work.
\end{abstract}

Keywords: chitosan; iron; yoghurt; gastrointestinal simulation; plant fibers 


\section{Introduction}

Chitin is an amino-polysaccharide containing $\beta-(1,4)$-linkages as is present in cellulose. It is a constituent of exoskeletons of arthropods and cell walls of most fungi. Chitosan, the principal chitin derivative, is a heteropolysaccharide consisting of linear $\beta$-1,4-linked GlcN and GlcNAc units. This carbohydrate polymer is resistant to hydrolysis by human endogenous enzymes and is biocompatible and biodegradable. Moreover, chitosan has no toxicity in animal organs [1-3].

The Codex Alimentarius Commission adopted a new definition of fiber in July 2009, designed to harmonize the use of the term around the world. It describes fiber as elements not hydrolyzed by endogenous enzymes in the small intestine (indigestibility) as well as having physiological effects beneficial to health. Dietary fibers are carbohydrate polymers with ten or more monomeric units and belonging to one of three categories of carbohydrates polymers: edible carbohydrate polymers naturally occurring in food, carbohydrate polymers which have been obtained from raw food material by physical, enzymatic, or chemical means (chitosan is included in this group); and synthetic carbohydrate polymers [4-6]. Because chitosan is an animal-origin carbohydrate polymer, which is included in the definition, it is being used as a new source of dietary fiber helping to meet consumer requirements all over the world that are increasingly interested in products high in dietary fiber $[7,8]$.

Minerals and trace elements have gained increasing interest in nutrition fields. Iron (Fe) deficiency is a leading nutritional concern worldwide, affecting $20-50 \%$ of the world's population [9]. There is an unequivocal need for predicting absorption of dietary iron [10]. The aim of most of the investigations in this field is to make evident that fiber may be an important determinant of the utilization of minerals in the diet. Much research has been done to better understand the physicochemical interactions between dietary fiber and minerals in the past decades [11-13]. Several of these investigations have applied in vitro digestive models to study iron absorption in foods [14-16]. Some studies have been done with cereal foods because of the known capacity of phytate to bind minerals $[17,18]$. However, few works have been done to study iron absorption from fermented milk products [19].

Yoghurt is one of the best known food products that may contain probiotics and is currently increasing supplementation with prebiotics, a type of fiber that stimulates the growth of specific bacteria in the gut [20]. Synbiotic is a new concept to describe this kind of product and is popular among dairy manufactures in Europe [21]. In addition, yoghurt is a suitable food for iron fortification because fermentation markedly increases iron dialyzability and ferrous sulfate is known as having the highest bioavailability [22].

Considering the fact that chitosan is a new ingredient widely applied in foods and that there is a need of recognizing enhancers and inhibitors of iron absorption, the current work was designed to study the interaction of chitosan with iron when it was added to yoghurt as a food model. This interaction, evaluated as iron percentage retention, was compared with the behavior of different plant fibers: wheat, bamboo, apple, Psyllium and inulin. To chemically characterize the fibers used in this work, initial measurements of total solubility, insolubility, NDF (Neutral Detergent Fiber), ADF (Acid Detergent Fiber), cellulose, hemicellulose and lignin were taken. Then an in vitro digestive model was employed to quantify iron retention percentages of chitosan and different plant fibers. 


\section{Results and Discussion}

Trends in the area of food and nutrition include the introduction of new ingredients, like chitosan, to make functional foods. Consequently, there is a continuous need for predicting the interactions between chitosan and mineral nutrients, like iron.

In a previous work, we studied sensory and rheological properties of yoghurts fortified with the same plant fibers as we used in the present article (apple, bamboo, inulin and wheat) [23]. Moreover, we evaluated the interaction of chitosan and oil, using an in vitro chemical experimental model of the human digestive tract (gastric and duodenal environment) [24]. In another work we demonstrated that when chitosan is added to a food like yoghurt, both glucose and calcium availabilities are decreased and this effect is more pronounced than that produced by plant fibers. We also demonstrated using the Association of Official Analytical Chemists (AOAC) method, that fiber content in chitosan samples was higher than $92 \%$ [25]. All these results allow us to confirm that chitosan behaves as a dietary fiber. Based on the premise that yoghurt is a good vehicle for both viable probiotics and prebiotics, and it is a suitable food for iron fortification, we studied chitosan interaction with iron from yoghurt as a food model.

\subsection{Characterization of Fibers}

The dietary fibers used in this study have different water solubility characteristics: inulin is a soluble fiber, bamboo and wheat are insoluble fibers, apple is partially insoluble fiber, and psyllium forms a viscous dispersion at concentrations below $1 \%$ and a clear gelatinous mass at $2 \%$. Chitosan is a fiber of a different origin, i.e. from animal source and is soluble in an acidic medium and flocculates in an alkaline medium. We used these fibers because they present different physicochemical behaviors that have been described in literature $[2,26]$. The commercial fiber compositions used in this study, regarding total, soluble and insoluble fractions, are shown in Table 1. Analysis for dietary fiber using the AOAC method 991.43 showed that wheat and bamboo have high amounts of insoluble fraction.

Table 1. Characterization of fibers: Total, soluble and insoluble fiber content $(\mathrm{g} / 100 \mathrm{~g})$ according to the enzymatic-gravimetric method of the Association of Official Analytical Chemists (AOAC) Official Method 991.43 [27].

\begin{tabular}{cccccc}
\hline Fiber & $\begin{array}{c}\text { Insoluble fiber } \\
(\mathbf{g} / \mathbf{1 0 0 g})\end{array}$ & $\begin{array}{c}\text { \% Insoluble } \\
\text { fiber }\end{array}$ & $\begin{array}{c}\text { Soluble fiber } \\
\mathbf{( g / \mathbf { 1 0 0 g } )}\end{array}$ & $\begin{array}{c}\text { \% Soluble } \\
\text { fiber }\end{array}$ & $\begin{array}{c}\text { Total } \\
\text { fiber }\end{array}$ \\
\hline Apple & $44.8 \pm 0.4$ & 77.1 & $13.3 \pm 0.7$ & 22.9 & $58.1 \pm 1.0$ \\
Bamboo & $91.4 \pm 0.5$ & 95.9 & $3.2 \pm 0.8$ & 3.4 & $95.3 \pm 0.9$ \\
Chitosan & $98.0 \pm 1.0$ & 100 & nd & nd & $98.0 \pm 1.0$ \\
Inulin & nd & nd & $\geq 85.5$ & 100 & $\geq 85.5$ \\
Psyllium & $37.5 \pm 0.6$ & 82.9 & $7.1 \pm 0.5$ & 15.7 & $45.2 \pm 0.8$ \\
Wheat & $92.1 \pm 0.6$ & 97.6 & $2.3 \pm 0.6$ & 2.4 & $94.4 \pm 1.1$ \\
\hline
\end{tabular}

Inulin presents only soluble fraction in concordance with suppliers. Psyllium and apple have both soluble and insoluble fractions. The total dietary fiber content is $45.2 \%$ for psyllium, which is an acceptable value, taking into account that the supplier declared a $49.15 \%$ of Plantago ovata seed husk in Metamucil preparation and Van Craeyveld et al. [28] reported 3.4\% (dm) ash and 7.1\% (dm) protein 
contents for Plantago ovata seed husks. The total dietary fiber content is $58.1 \%$ for apple, which is about 10-14\% higher than the values reported by Sudha et al. [29], however, this value was in accordance with suppliers.

The chitosan used in this study has $98 \%$ of insoluble fraction and no detectable soluble fraction. Furthermore the characteristics of this biopolymer are a deacetylation degree of $89 \%$, a viscosity of $120 \mathrm{mPa} . \mathrm{s}$, a $6.7 \mathrm{~g} \%$ moisture and a $0.67 \mathrm{~g} \%$ ash content.

Plant fiber characterizations were completed with the study of Acid Detergent Fiber (ADF) and Neutral Detergent Fiber (NDF), lignin, cellulose and hemicellulose contents (Table 2). Apple presents the highest lignin content. Wheat fiber mainly has cellulose. Bamboo has proportional amounts of cellulose and hemicellulose, but compared with other fibers, has the highest hemicellulose content. These results are in accordance with their plant fiber origins and previous works [28-30]. Frutafit-Inulin was not analyzed because its composition was $\geq 85.5 \%$ (w/w) of inulin, $\leq 9.5 \%$ of mono and disaccharides, $\leq 0.1 \%$ of ash with degree of polymerization $\geq 9$ according to suppliers. Chitosan was not analyzed either, because of its animal origin.

Table 2. Plant fiber contents of main cell wall constituents (lignin, cellulose, hemicellulose) determined by a modification of the method described by Robertson and Van Soest [31] using ANKOM200/220 Fiber Analyzer. ADF: Acid Detergent Fiber; NDF: Neutral Detergent Fiber.

\begin{tabular}{cccccc}
\hline Fiber & ADF & NDF & Lignin & Cellulose & Hemicellulose \\
\hline Apple & $38.6 \pm 0.9$ & $44.3 \pm 0.7$ & $8.4 \pm 0.8$ & $30.2 \pm 1.7$ & $5.7 \pm 1.6$ \\
Bamboo & $50.2 \pm 0.7$ & $90.4 \pm 0.6$ & $5.0 \pm 0.3$ & $45.2 \pm 1.0$ & $40.2 \pm 1.7$ \\
Psyllium & $7.3 \pm 0.4$ & $36.8 \pm 0.9$ & $0.8 \pm 0.1$ & $6.5 \pm 0.4$ & $29.5 \pm 1.3$ \\
Wheat & $74.8 \pm 0.3$ & $89.7 \pm 0.6$ & $2.6 \pm 0.4$ & $72.2 \pm 0.7$ & $14.9 \pm 0.9$ \\
\hline
\end{tabular}

Scientists who deal with animal nutrition usually use Van Soest's method to analyze feed. Scientists working on human nutrition use methods of the AOAC, because of their interest in soluble fiber. It is known that soluble fiber plays an important role in human health and the food industry. However, it could be useful in human nutrition to know the composition of insoluble fiber, as it is possible that insoluble fibers do not all have the same effect on human health. The NDF and insoluble fiber methods were applied to the same samples. Insoluble fiber includes hemicellulose, cellulose, lignin, cutin, suberin, chitin, chitosan, waxes and resistant starch. NDF includes hemicellulose, cellulose and lignin. Escarnot et al. [32] studied three wheat varieties and four spelt genotypes. They analyzed three milling fractions from those grains for insoluble and soluble fiber contents, lignin, hemicellulose and cellulose. They found a very high correlation $\left(\mathrm{r}^{2}=0.99\right)$ between the two methods, showing that NDF and insoluble fiber methods cover the same types of fiber. For insoluble fiber analysis, the NDF method is faster and more thorough.

\subsection{Digestive Chemical Model and Iron Retention Percentages}

In vitro digestion approaches have obvious limitations, but they have been employed as a useful tool, particularly for screening samples before elaborating in vivo and expensive human studies. In the present study, the introduction of cellulose dialysis tubes in the digestive chemical experimental model 
is utilized to study iron retention by the fibers tested. The use of a membrane dialysis tube reproduces, in the laboratory, the duodenum wall and according to Miret et al. [33] its utilization, is presumably a significant factor that determines iron absorption. This type of model allows current research needs for fast, cheap and efficient experimental procedures. Digestive enzymes were not utilized in this model because they do not hydrolyze fibers. The importance of duodenal simulation in this study is because most dietary iron is absorbed in the duodenum.

In this work, yoghurts with each type of fiber are added with $0.8 \%(\mathrm{w} / \mathrm{w})$ of ferrous sulfate. In yoghurt, caseins are modified as a consequence of its production process. Bioactive peptides are formed from caseins during the elaboration of milk products (cheese, yoghurt) under the action of endogenous enzymes of milk (plasmin, cathepsin, among others) or of microorganisms [34].These peptidic fragments that are already present in yoghurt, could fix iron according to Bouhallab and Bouglé [34]. Then, these complex matrixes (yoghurts with each type of fiber and iron) are subjected to the gastrointestinal simulation. A control yoghurt with ferrous sulfate without fiber was also subjected to the digestive simulation and considered to be $0 \%$ iron retention ( $100 \%$ iron dialyzated) to calculate iron retention percentages for each fiber. With this control yoghurt, we could consider the interaction of iron with casein peptidic fragments.

Simulation of gastrointestinal environment of different yoghurts can be observed in Figure 1 (before dialysis) and Figure 2 (during dialysis). Changes in $\mathrm{pH}$ during gastrointestinal simulation produces different behaviors depending on the type of fiber employed. Apple fiber shows brownish color (Figure 1), probably due to the content of phenolics compounds [35]. In Figure 2 it can be seen that Psyllium fiber gives a viscous dispersion [36,37]. Due to changing $\mathrm{pH}$ values in the digestive tract, Chitosan precipitates while passing through the first portion of the small intestine, forming flocculus. Chitosan a positively charged polysaccharide that is insoluble in neutral and alkaline $\mathrm{pH}$. It is only soluble in acidic $\mathrm{pH}$ because below $\mathrm{pH} 6.5\left(\mathrm{pK}_{\mathrm{a}}=6.5\right)$, the amine groups of chitosan are positively charged. When it is solubilized in dilute acid, chitosan has a linear structure [38]. At $\mathrm{pH}>6.5$, the polymer loses its charges from the amine groups and therefore becomes insoluble in water and precipitate forming flocculus.

When chitosan is added to yoghurt, one might think that chitosan would remain soluble. However, yoghurt contains peptidic fragments from caseins. The caseins are amphiphilic phosphoproteins and their isoelectric point ( $\mathrm{p} I$ ) value is 4.6 . At $\mathrm{pH}$ above the $\mathrm{p} I$, caseins are negatively charged and soluble in water. The caseins have an electronegative domain preferentially located in small peptidic fragments known as $\alpha_{\mathrm{s} 1}$-Casein, $\beta$-casein and $\kappa$-casein [39]. These structural features of the caseins may render these molecules adept at forming complexes with multivalent cationic macromolecules, such as chitosan [38]. In yoghurt ( $\mathrm{pH}=4.4-4.6$ ) aggregation of the casein-peptide-fragments occur because of a reduction in the electrostatic repulsion at around their $\mathrm{pI}$ value. 
Figure 1. Simulation digestive mediums of different fibers before dialysis $\left(37^{\circ} \mathrm{C}, \mathrm{pH} 6.8-7.2\right.$ with $0.2 \mathrm{M} \mathrm{NaHCO}_{3}$ and stirring speed $300 \mathrm{rpm}$ to reproduce the chemical duodenal environment). (1) Inulin, (2) Bamboo, (3) Psyllium, (4) Chitosan, (5) Wheat, (6) Apple.

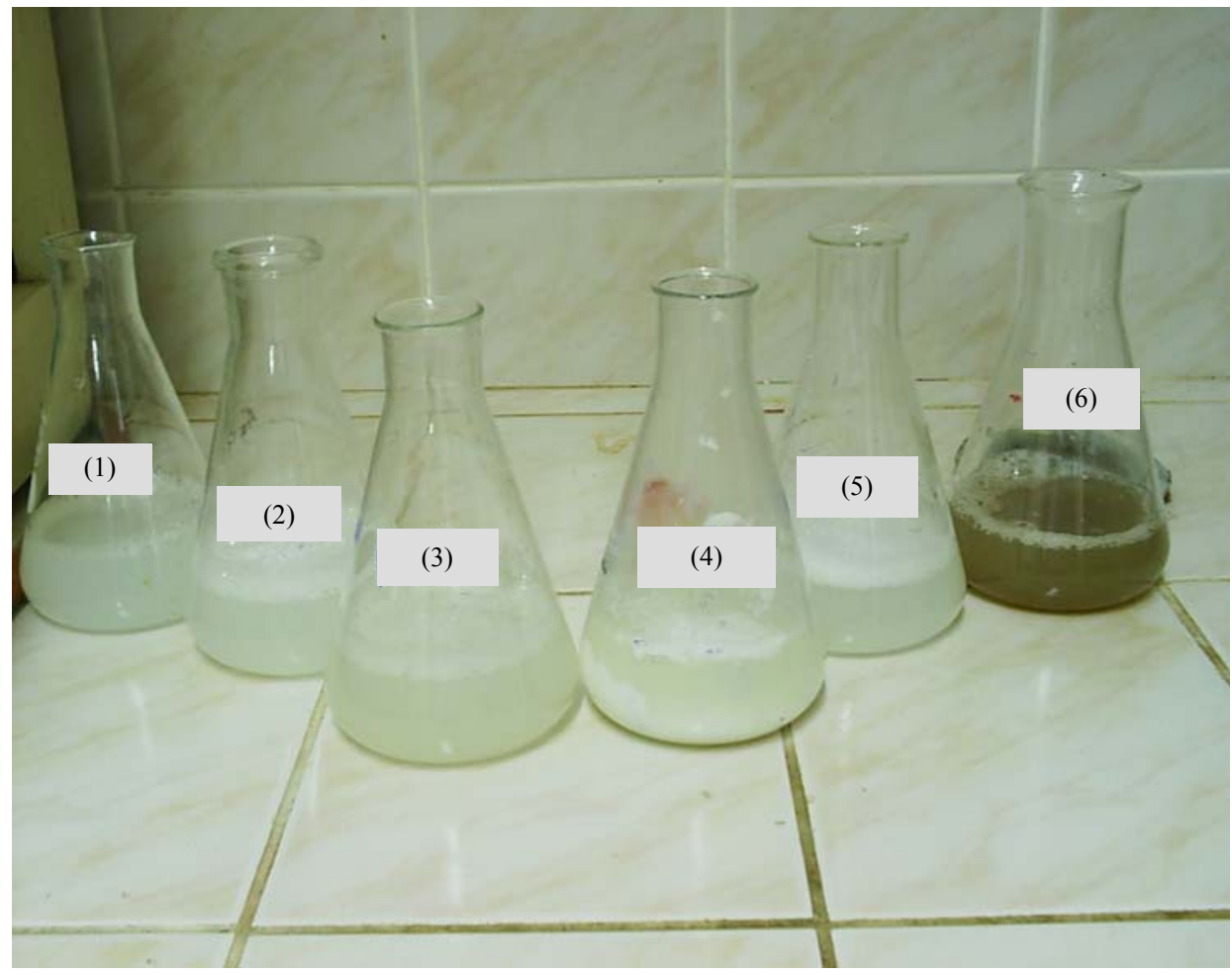

Figure 2. Different fiber behaviors in the dialysis step of digestive simulation. (1) Yoghurt without fiber, (2) Chitosan, (3) Psyllium, (4) Wheat.

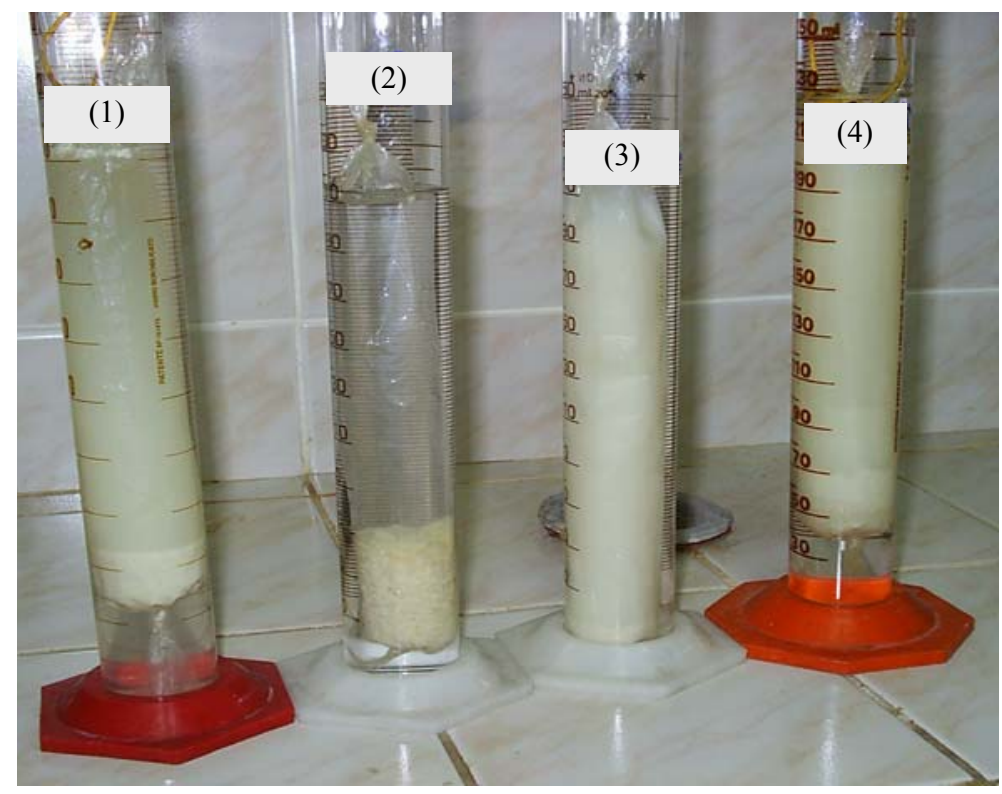

Anal et al. [38] studied the interactions between sodium caseinate and chitosan, under a range of conditions. This study showed that soluble or insoluble chitosan-caseinate complexes can be formed depending on the $\mathrm{pH}$. The characteristics of the complexes are determined by the biopolymer types and their concentration, as well as by environmental conditions. In a certain $\mathrm{pH}$ range (5.0-6.0), 
nanocomplexes of chitosan and sodium caseinate with diameter between 250 and $350 \mathrm{~nm}$ were formed. The chitosan and sodium caseinate complexes associated to form larger particles, which resulted in phase separation appear when the $\mathrm{pH}$ was either in the range $4.0-4.5$ or $>6.5$. At $\mathrm{pH} 3.0-3.8$, where chitosan and sodium caseinate have similar charges, they may dissociate from each other and become solubilized in solution.

According to these authors, yoghurts with chitosan could contain chitosan-casein-peptidic complexes apart from free chitosan molecules in solution. Besides, we add iron which could interact with free chitosan molecules and those complexes. In our work, yoghurt with chitosan and iron is subjected to the gastrointestinal simulation. In the first step, our food passes through the simulated stomach $(\mathrm{pH}=1.0-2.0)$ and it could be expected that caseins peptidic fragments, chitosan and iron all remain in solution. Changes in $\mathrm{pH}$, while the food passes through the first portion of the simulated small intestine, can lead to formation of chitosan-casein peptidic complexes and iron could be interacting with them. At pH 6.8-7.0, free chitosan molecules and chitosan-casein-peptidic complexes precipitate forming flocculus. The force of the coagulum formed is high and can be seen in Figures 1 and 2. The results reported by Ausar et al. [39] indicate that hydrophobicity of the casein-chitosan complex is the main mechanism by which the casein-chitosan flocculation is produced. Iron retention percentages of different fibers are presented in Figure 3. Bamboo and wheat fibers, both insoluble, have low iron retention percentages between $2-5 \%$ at $30 \mathrm{~min}$ with a maximum of $10 \%$ at $60 \mathrm{~min}$. There are no significant differences $(p<0.05)$ between them by Tukey's test.

Figure 3. Retention percentages of yoghurts with different studied fibers.

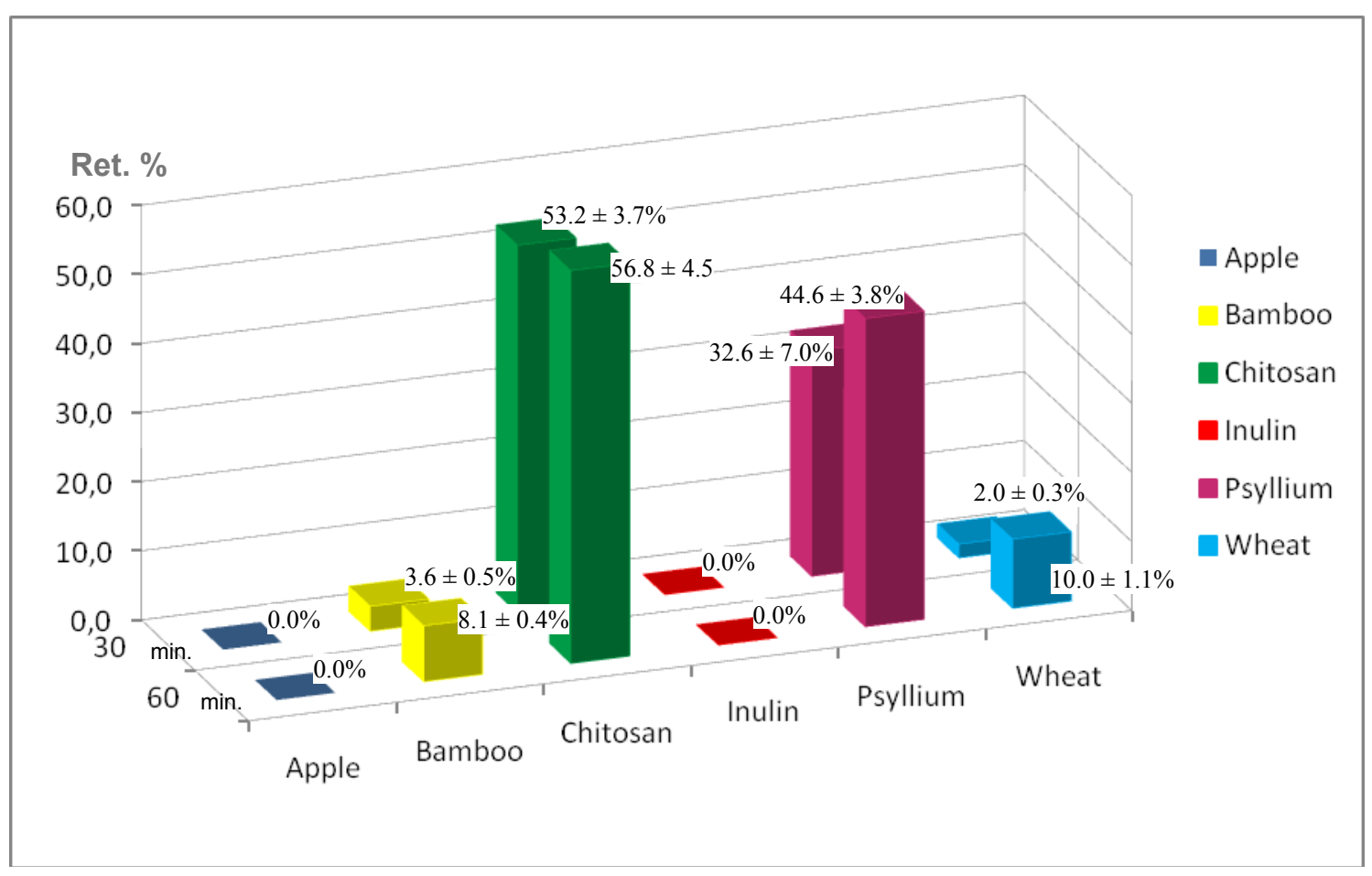

Bamboo and wheat are high in cellulose content. Cellulose could retain iron by physical adsorption according to results reported by Torre et al. [13]. They worked with high dietary fiber food materials studying the physicochemical interactions with $\mathrm{Fe}(\mathrm{II}), \mathrm{Fe}(\mathrm{III})$ and $\mathrm{Ca}(\mathrm{II})$ without an in vitro digestive 
model. They found that the interaction between Fe(II) and cellulose could be explained better by physical adsorption than complex formation.

Inulin, a soluble fiber, has no iron retention in either assay. This result is in accordance with studies that confirm that inulin does not interfere with iron absorption [20,40-42].

Although psyllium and apple fiber contain both soluble and insoluble fractions, they have significantly different responses $(\mathrm{p}<0.05)$. The apple fiber incorporated in yoghurt has no influence on iron retention. Psyllium shows, on average, $44.6 \pm 3.8 \%$ iron retention at $60 \mathrm{~min}$, which may be mainly attributed to the formation of high viscous dispersion that could be interfering with iron absorption (Figure 2). In addition, the differing behaviors between apple fiber and psyllium could be explained by the different chemical composition of these fibers. Psyllium has high hemicellulose content and apple has the highest lignin content and cellulose. However, bamboo has a low iron retention percentage although its hemicellulose content, $(40.2 \pm 1.7)$, is probably because it has cellulose $(45.2 \pm 1.0)$ and lignin $(5.0 \pm 0.3)$.

Chitosan presents the highest iron retention percentages at $30 \mathrm{~min}(53.2 \pm 3.7 \%)$ and $60 \mathrm{~min}$ $(56.8 \pm 4.5 \%)$, which shows significant differences $(\mathrm{p}<0.05)$ with other fibers. This biopolymer, which has an animal origin, contains $98 \%$ insoluble fiber, and flocculates in the first portion of the small intestine. These flocculus (Figure 2), which could entrap iron, clearly decrease iron dialysis. However, certain amount of iron could go through the cellulose membrane and could be measured to calculate the iron retention percentage. Certain amount of casein-peptide-fragments interacting with iron could remain in solution. Nevertheless, their presence does not interfere with the calculation of iron retention percentages as proven by the digestive simulations performed with control yoghurts. Chitosan is essentially a positively charged polysaccharide and iron is a cation. Anal et al. [38] measured zeta potential of chitosan solutions, sodium caseinate solutions and chitosan-caseinate mixtures in a range of $\mathrm{pH}(3.0-6.5)$. They found that the pure chitosan solutions were strongly positively charged between $\mathrm{pH} 3.0$ and 6.0. The zeta potential values of chitosan solutions decreased with increasing $\mathrm{pH}$ and were slightly negative (approximately $-2.5 \mathrm{mV}$ ) at $\mathrm{pH} 6.5$. In our study, in this range of $\mathrm{pH}$ (3.0-6.0), isolated molecules of chitosan were probably interacting with iron by adsorption rather than by electrostatic forces. Besides, Anal et al. [38] found that the zeta potentials of the chitosan-caseinate solutions were negative at $\mathrm{pH}>5.5$. In this range of $\mathrm{pH}$, in our work, electrostatic interaction could exist between chitosan-caseinate complexes and iron. However, when chitosan precipitates, it captures the iron whether iron interacts with chitosan by electrostatic forces or by adsorption.

This study shows that the effect of chitosan on iron absorption is more pronounced and higher than those measured for the other studied plant fibers, as dietary fiber is a significant factor that influences iron absorption. In the same way, we observed with an in vitro study, that when chitosan is added to a food like yoghurt, glucose and calcium availabilities are decreased and this effect is more pronounced than with the other fibers [24]. The iron retention percentages of different fibers used in this work could be explained mainly as a result of physicochemical phenomena, like adsorption, formation of viscous dispersion and flocculus.

In vitro methods cannot be used alone for important decisions taken by industry or international organizations because human studies are required for such determinations [43]. The findings presented 
in this study may be used to increase the understanding of the interactions between chitosan and plant fibers with minerals like iron, for screening purposes.

\section{Experimental Section}

\subsection{Chitosan}

Chitosan was obtained from crustacean chitin in the Laboratorio de Investigación Básica y Aplicada en Quitina (LIBAQ-INQUISUR-CONICET), Universidad Nacional del Sur, Bahía Blanca, Argentina. Chitin firstly was isolated from shrimp (Pleoticus mülleri) waste by the process that was described in our previous work [25].

Chitosan was prepared directly by heterogeneous deacetylation of chitin with $50 \%(\mathrm{w} / \mathrm{w}) \mathrm{NaOH}$. For the biopolymer characterization, moisture and ash contents were determined at $100-105{ }^{\circ} \mathrm{C}$ and $500-505{ }^{\circ} \mathrm{C}$, respectively. Deacetylation degree was obtained using FT-IR spectroscopy (Nicolet iS10 FT-IR Spectrometer, Thermo Fisher Scientific, USA) with samples in the form of KBr at a ratio of 1:2. Viscosity of $1 \%$ chitosan in $1 \%$ acetic acid solution was measured with a Brookfield model DV-IV + viscosimeter (Brookfield, USA) with spindle 21 and a $50 \mathrm{rpm}$ rotational speed at $25{ }^{\circ} \mathrm{C}$.

\subsection{Plant Fibers}

The fibers used were: inulin (Frutafit-inulin, Imperial Sensus, The Netherlands), bamboo (Qualicel, CFF, Gehren, Germany), wheat (Vitacel WF 101, JRS, Rosenberg, Germany), apple (Vitacel AF 400-30, JRS, Rosenberg, Germany) and psyllium (Metamucil, Procter and Gamble Co., Cincinnati, $\mathrm{OH}, \mathrm{USA})$. Metamucil is a pharmaceutical formula with Plantago ovata seed husk $(49.15 \% \mathrm{w} / \mathrm{w})$ and sucrose (50.85\%). Suppliers of wheat and apple fiber indicated that these products are free from phytic acid, and besides, the wheat fiber is gluten free. The inulin utilized in this work has a degree of polymerization $\geq 9$ as declared by suppliers.

\subsection{Analysis for Dietary Fiber}

Total, soluble and insoluble dietary fiber contents of chitosan and plant fibers were analyzed according to the enzymatic-gravimetric method of the Association of Official Analytical Chemists (AOAC) Official Method 991. 43 [27].

Apple, bamboo, psyllium and wheat fibers were investigated to obtain contents of main cell wall constituents (lignin, cellulose, hemicellulose). These components were determined by modifications of the method described by Robertson and van Soest [31] using ANKOM200/220 Fiber Analyzer (ANKOM Technology, Macedon, NY, USA). This method measures Acid Detergent Fiber (ADF), Neutral Detergent Fiber (NDF) and Lignin. Cellulose and hemicellulose contents were obtained by calculations. To determine ADF, duplicate samples were agitated under pressure with hot acid detergent solution for $60 \mathrm{~min}$, rinsed in hot water and dried. To determine lignin content, duplicated samples were digested in $72 \%(\mathrm{v} / \mathrm{v})$ sulfuric acid, following ADF analysis. Cellulose content of samples was calculated from ADF minus the lignin content. To determine NDF, duplicated samples were shaken with neutral detergent solution and heat-stable $\alpha$-amylase for $60 \mathrm{~min}$, rinsed and dried. Hemicellulose content of samples was calculated as NDF minus ADF. 


\subsection{Yoghurt Preparation}

Yoghurt was prepared using reconstituted whole milk powder with $15 \%$ and 5\% sucrose. This mix was homogenized and heated to $85{ }^{\circ} \mathrm{C}$ for $30 \mathrm{~min}$., cooled to ambient temperature and inoculated with $0.03 \%$ starter culture [23]. Starter was constituted by a 1:1 mixture of Streptococcus thermophilus (CIDCA collection 321) and Lactobacillus delbrueckii subsp. bulgaricus (CIDCA collection 332) [44]. Samples were incubated at $43{ }^{\circ} \mathrm{C}$ to reach a pH of 4.4-4.6 and stored at $4{ }^{\circ} \mathrm{C}$, after completion of the fermentation process [45].

Samples of yoghurt were added with $1.3 \%(\mathrm{w} / \mathrm{w})$ of each dietary fiber. The amount of fiber was selected following US regulations for fiber-fortified products [46]. Besides, yoghurts with each type of fiber were added with $0.8 \%(\mathrm{w} / \mathrm{w})$ of ferrous sulfate. This addition was in accordance with local regulations governing iron supplementation in milk products. Ferrous sulfate $\left(\mathrm{FeSO}_{4} \cdot 7 \mathrm{H}_{2} \mathrm{O}\right)$ of $99.9 \%$ purity was used as purchased (Sigma-Aldrich Co., St. Louis, MO, USA).

\subsection{Digestive Chemical Experimental Model}

A digestive chemical experimental model was performed to study the interaction of dietary fiber with iron, obtaining iron retention percentages. Experiments were carried out in the following manner.

Yoghurts with ferrous sulfate and each fiber were stirred in $50 \mathrm{~mL}$ of $0.1 \mathrm{M} \mathrm{HCl}$ (Merck) for $1 \mathrm{~h}$ at $\mathrm{pH} 1.0-2.0,30 \mathrm{rpm}$ and $37^{\circ} \mathrm{C}$ to reproduce the gastric environment. $\mathrm{PH}$ was checked each 15 min with a pH Meter Hach model EC-30 (USA) during this first step of simulation and it remained constant ( $\mathrm{pH} 1.0-2.0)$.

The $\mathrm{pH}$ level of these mixes was then increased to $\mathrm{pH}$ 6.8-7.2 with 0.2 $\mathrm{M} \mathrm{NaHCO}_{3}$ (Sigma-Aldrich Co., St. Louis, MO, USA) to reproduce the chemical duodenal environment. The stirring speed was increased from 30 to $300 \mathrm{rpm}$ to imitate the peristaltic movement and temperature was maintained at $37{ }^{\circ} \mathrm{C}$. After 3 min to addition of $\mathrm{NaHCO}_{3}, \mathrm{pH}$ was measured $(\mathrm{pH}$ 2.5-3.5) and mixes were immediately transferred into a dialysis tubing cellulose membrane (D9527-100 FT, (Sigma-Aldrich Co., St. Louis, MO, USA). This cellulose membrane (molecular weight cut-off 12,400) was previously prepared, as indicated by suppliers, and it was cut into $28 \mathrm{~cm}$ length pieces. The loaded tubes were immersed in $100 \mathrm{~mL}$ of distilled water; at $37{ }^{\circ} \mathrm{C}$. Iron concentrations were determined from the dialyzed medium at 30 and 60 minutes. A control yoghurt with ferrous sulfate without fibers was subjected to the digestive simulation and was considered as $0 \%$ iron retention ( $100 \%$ iron dialyzated) to calculate iron retention percentages for each fiber.

\subsection{Iron Content Determination}

To determine iron concentration in the dialyzates a spectrophotometric method was used. Iron was reduced with mercaptoacetic acid (succinic acid buffer, $\mathrm{pH}$ 3.7). Then, it reacted with piridil bis-fenil trazine sulfonate (PBTS) producing a pink color due to the complex formed (Wiener Lab Fe-colour Kit, Rosario, Argentina). Two $\mathrm{mL}$ of reducing medium was mixed with $500 \mu \mathrm{L}$ of dializated and the absorbance was read on a spectrophotometer (Spectronic 20 Genesys, Thermo Electron Scientific Instruments Corp., Madison, WI, USA) at $560 \mathrm{~nm}$ (internal blank). Immediately, one drop of PBTS was added, the solution was mixed, and absorbance was read again after 5 min. All glassware used in 
sample preparation and analysis was rinsed with $10 \%(\mathrm{v} / \mathrm{v})$ concentrated $\mathrm{HCl}(37 \%)$ and deionized water before using, to avoid mineral contamination. A regression equation $(\mathrm{y}=2.5333 \mathrm{x}+0.0042$, $\left.\mathrm{R}^{2}=0.995\right)$ derived from data generated from standards of $\mathrm{Fe}_{2} \mathrm{SO}_{4}$ was used to calculate iron concentrations in the samples.

\subsection{Iron Retention Percentage Calculations}

Iron retention percentages for each studied fibers were calculated as a percentage of the amount of iron measured in the dialyzed medium obtained with the control yoghurt without fibers.

\subsection{Statistical Analysis}

Experiments were performed at least nine times for each dietary fiber using freshly prepared yoghurt. For total iron concentration in dialyzates, each individual sample was run in duplicate. Averages and standard deviations were calculated and expressed in each case as the mean \pm SD for $n$ replicates. Normality of the data was checked with the Lilliefors test. The influence of different dietary fibers on the iron retention percentage was statistically analyzed by a one-way analysis of variance (ANOVA) to find significant differences $(p<0.05)$ and Tukey's test was used to compare means.

\section{Conclusions}

This study showed that chitosan had the highest iron retention percentage when it was added to a food like iron-fortified yoghurt, as determined by an in vitro digestive chemical model. The iron retention percentages of the different fibers used in this work could be explained mainly as a result of physicochemical phenomena, like adsorption, formation of viscous dispersion and formation of flocculus. Chitosan interacted in a more pronounced manner with iron than the plant fibers evaluated under the same conditions.

\section{Acknowledgements}

Financial support from CONICET and SeCyT-Universidad Nacional del Sur is gratefully acknowledged. Marina Dello Staffolo, Miriam Martino and Alicia Bevilacqua express their gratitude to Universidad Nacional de La Plata and bamboo, inulin and wheat suppliers (Imperial Sensus, CFF and JRS).

\section{References}

1. Arai, K.; Minumari, K.; Fujita, T. On the toxicity of chitosan. Bull. Tokai Reg. Fish. Res. Lab. 1968, 56, 889-892.

2. Kumar, M.N.V.R.; Muzzarelli, R.A.A.; Muzzarelli, C.; Sashiwa, H.; Domb, A.J. Chitosan chemistry and pharmaceutical perspectives. Chem. Rev. 2004, 104, 6017-6084.

3. Harish Prashanth, K.V.; Lakshman, K.; Shamala, T.R.; Tharanathan R.N. Biodegradation of chitosan-graft-polymethylmethacrylate films. Int. Biodeterior. Biodegrad. 2005, 56, 115-120.

4. Cummings, T.J.; Mann, J.; Nishida, C.; Vorster, H. Dietary fibre: An agreed definition. Lancet 2009, 373, 365-366. 
5. Harris, S.S.; Pijls, L. Dietary fibre: Refining a definition. Lancet 2009, 374, 28.

6. Phillips, G.O.; Cui, S.W. An introduction: Evolution and finalisation of the regulatory definition of dietary. Food. Hydrocolloid. 2010, 25, 139-143.

7. Harish Prashanth, K.V.; Tharanathan, R.N. Chitin/chitosan: Modifications and their unlimited application potential. Trends Food Sci. Technol. 2007, 18, 117-131.

8. Elleuch, M.; Bedigian, D.; Roiseux, O.; Besbes, S.; Blecker, C.; Attia, H. Dietary fibre and fibre-rich by-products of food processing: Characterization, technological functionality and commercial applications: A review. Food Chem. 2011, 124, 411-421.

9. Beard, J.; Stoltzfus, R.J. Iron-deficiency anemia: Reexamining the nature and magnitude of the public health problem. J. Nutr. 2001, 131, 563S-703S.

10. Yasuda, K.; Roneker, K.R.; Miller, D.D.; Welch, R.M.; Lei, X.G. Supplemental dietary insulin affects the bioavailability of iron in corn and soybean meal to young pigs. J. Nutr. 2006, 136, 3033-3038.

11. Thompson, S.A.; Weber, C.W. Influence of $\mathrm{pH}$ on the binding of copper, zinc and iron in six fiber sources. J. Food. Sci. 1979, 44, 752-754.

12. Laszlo, J.A. Mineral binding properties of soy hull. Modelling mineral interactions with an insoluble dietary fiber source. J. Agric. Food. Chem. 1987, 35, 593-600.

13. Torre, M.; Rodriguez, A.R.; Saura-Calixto, F. Interactions of $\mathrm{Fe}(\mathrm{II}), \mathrm{Ca}(\mathrm{I} 1)$ and $\mathrm{Fe}(\mathrm{II} 1)$ with high dietary fibre materials: A physicochemical approach. Food Chem. 1995, 54, 23-31.

14. Leigh, M.J.; Miller, D.D. Effects of $\mathrm{pH}$ and chelating agents on iron binding by dietary fiber. Implications for iron availability. Am. J. Clin. Nutr. 1983, 38, 202-213.

15. Shen, H.; Luten, J.; Robberecht, H.; Bindels, J.; Deelstra, H. Modification of an in vitro method for estimating the bioavailability of zinc and calcium from foods. Z. Lebensm. Unters. Forsch. 1994, 199, 442-445.

16. Argyri, K.; Birba, A.; Miller, D.D.; Komaitis, M.; Kapsokefalou, M. Predicting relative concentrations of bioavailable iron in foods using in vitro digestion: New developments. Food Chem. 2009, 113, 602-607.

17. Vitali, D.; Vedrina-Dragojević, I.; Šebečić, B.; Vujić, L. Impact of modifying tea-biscuit composition on phytate levels and iron content and availability. Food Chem. 2007, 102, 82-89.

18. Kumar, V.; Sinha A.K.; Makkar, H.P.S.; Becker, K. Dietary roles of phytate and phytase in human nutrition: A review. Food Chem. 2010, 120 (4), 945-959.

19. Hur, S.J.; Lim, B.O.; Decker E.A.; McClements, D.J. In vitro human digestion models for food applications. Food Chem. 2011, 125, 1-12.

20. Laparra, J.M.; Tako, E.; Glahn, R.P.; Miller, D.D. Supplemental inulin does not enhance iron bioavailability to Caco-2 cells from milk- or soy-based, probiotic-containing, yoghurts but incubation at $37^{\circ} \mathrm{C}$ does. Food Chem. 2008, 109, 122-128.

21. Yeung, C.K.; Glahn, R.P.; Welch, R.M.; Miller, D.D. Prebiotics and iron bioavailability-Is there a connection? J. Food Sci. 2005, 70, 88-92.

22. Drago, S.R.; Valencia, M.E. Effect of fermentation on iron, zinc, and calcium availability from iron-fortified dairy products. J. Food Sci. 2002, 67, 3130-3134.

23. Dello Staffolo, M.; Bertola, N.; Martino, M.; Bevilacqua, A. Influence of dietary fibre addition on sensory and rheological properties of yoghurt. Int. Dairy J. 2004, 14, 263-268. 
24. Rodríguez, M.; Albertengo, L. Interaction between chitosan and oil under stomach and duodenal digestive chemical conditions. Biosci. Biotechnol. Biochem. 2005, 69, 2057-2062.

25. Rodríguez, M.S.; Montero, M.; Dello Staffolo, M.; Martino, M.; Bevilacqua, A.; Albertengo, L. Chitosan influence on glucose and calcium availability from yoghurt: In vitro comparative study with plants fibre. Carbohyd. Polym. 2008, 74, 797-801.

26. Tungland, B.; Meyer, D. Nondigestible oligo- and polysaccharides (dietary fiber): Their physiology and role in human health and food. Compr. Rev. Food Sci. Food Saf. 2002, 3, 73-91.

27. Total, soluble, and insoluble dietary fibre in foods. AOAC Official Methods 991.43. Official Methods of Analysis, 16th ed.; Cunniff, P., Ed.; AOAC International: Arlington, VA, USA, 1995; Chapter 32, pp. 7-9.

28. Van Craeyveld, V.; Delcour, J.A.; Courtin, C.M. Extractability and chemical and enzymic degradation of psyllium (Plantago ovata Forsk) seed husk arabinoxylans. Food Chem. 2009, 112, 812-819.

29. Sudha, M.L.; Baskaran, V.; Leelavathi, K. Apple pomace as a source of dietary fiber and polyphenols and its effect on the rheological characteristics and cake making. Food Chem. 2007, 104, 686-692.

30. Dierenfeld, E.S.; Hintz, H.F.; Robertson, J.B.; van Soest, P.J.; Oftedal, O.T. Utilization of bamboo by the giant panda. J. Nutr. 1982, 112, 636-641.

31. Robertson, J.B.; Van Soest, P.J. The detergent system of analysis and its applications to human foods. In The Analysis of Dietary Fiber and Food; James, W.P.T., Theander, O., Eds.; Marcel Dekker: New York, NY, USA, 1981; pp. 139-153.

32. Escarnot, E.; Agneessens, R.; Wathelet, B.; Paquot, M. Quantitative and qualitative study of spelt and wheat fibres in varying milling fractions. Food Chem. 2010, 122, 857-863.

33. Miret, S.; Simpson, R.J.; McKie, A.T. Physiology and molecular biology of dietary iron absorption. Annu. Rev. Nutr. 2003, 23, 283-301.

34. Bouhallab, S.; Bouglé, D. Biopeptides of milk: Caseinophosphopeptides and mineral bioavailability. Reprod. Nutr. Dev. 2004, 44, 493-498.

35. Sun-Waterhouse, D.; Farr, J.; Wibisono, R.; Saleh, Z. Fruit-based functional foods I: Production of food-grade apple fibre ingredients. Int. J. Food Sci. Technol. 2008, 43, 2113-2122.

36. Chan, J.K.C.; Wypyszyk, V.A. Forgotten natural dietary fiber: Psyllium mucilloid. Cereal Food. World 1988, 33, 919-922.

37. Fischer, M.H.; Yu, N.; Gray, G.R.; Ralph, J.; Andersond, L.; Marletta, J.A. The gel-forming polysaccharide of psyllium husk (Plantago ovata Forsk). Carbohyd. Res. 2004, 339, 2009-2017.

38. Anal, A.K.; Tobiassen, A.; Flanagan, J.; Singh, H. Preparation and characterization of nanoparticles formed by chitosan-caseinate interactions. Colloid. Surface. B 2008, 64, 104-110.

39. Ausar, S.F.; Bianco, I.D.; Badini, R.G.; Castagna, L.F.; Modesti, N.M.; Landa, C.A; Beltramo, D.M. Characterization of casein micelle precipitation by chitosans. J. Dairy Sci. 2001, 84, 361-369.

40. Van den Heuvel, E.G.; Schaafsma, G.; Muys; T.; van Dokkum, W. Nondigestible oligosaccharides do not interfere with calcium and nonheme-iron absorption in young, healthy men. Am. J. Clin. Nutr. 1998, 67, 445-451. 
41. Bosscher, D.; van Caillie-Bertrand, M.; van Cauwenbergh, R.; Deelstra, H. Availabilities of calcium iron and zinc from dairy infant formulas is affected by soluble dietary fibres and modified starch fractions. Nutrition 2003, 19, 641-645.

42. Azorín-Ortuño, M.; Urbán, C.; Cerón, J.J.; Tecles, F.; Allende, A.; Tomás-Barberán, F.A.; Espín, J.C. Effect of low inulin doses with different polymerisation degree on lipid metabolism, mineral absorption, and intestinal microbiota in rats with fat-supplemented diet. Food Chem. 2009, 113, 1058-1065.

43. Fairweather-Tait, S.; Lynch, S.; Hotz, C.; Hurrell, R.; Abrahamse, L.; Beebe, S.; Bering, S.; Bukhave, K.; Glahn, R.; Hambidge, M.; et al. The usefulness of in vitro models to predict the bioavailability of iron and zinc: A consensus statement from the Harvest Plus expert consultation. Int. J. Vitam. Nutr. Res. 2005, 7, 371-374.

44. Moreira, M.; Abraham, A.; De Antoni, G. Technological properties of milks fermented with thermophilic lactic acid bacteria at suboptimal temperature. J. Dairy Sci. 2000, 83, 395-400.

45. Tamine, A.; Robinson, R. Yoghurt Science and Technology, 3rd ed.; CRC Press: Boca Raton, FL, USA, 2007; Chapter 2.

46. Fernández-García, E.; McGregor, J.U. Fortification of sweetened plain yoghurt with insoluble dietary fibre. Z. Lebensm. Unters. Forsch. 1997, 204, 433-437.

(C) 2011 by the authors; licensee MDPI, Basel, Switzerland. This article is an open access article distributed under the terms and conditions of the Creative Commons Attribution license (http://creativecommons.org/licenses/by/3.0/). 